\title{
Evaluation of the systemic innate immune response and metabolic alterations of nonlactating cows with diet-induced subacute ruminal acidosis
}

\author{
J. C. Rodríguez-Lecompte, ${ }^{\dagger} \dagger^{1}$ A. D. Kroeker, ${ }^{*}$ A. Ceballos-Márquez, ${ }^{*} \ddagger$ S. Li, ${ }^{*}$ J. C. Plaizier, ${ }^{*}$ and D. E. Gomez§ \\ ${ }^{*}$ Department of Animal Science, University of Manitoba, Winnipeg, MB, Canada R3T 2N2 \\ †Department of Pathology and Microbiology, University of Prince Edward Island, Charlottetown, PEI, Canada C1A 4P3 \\ łDepartamento de Producción Agropecuaria, Universidad de Caldas, Manizales, Caldas, Colombia \\ §Department of Health Management, University of Prince Edward Island, Charlottetown, PEI, Canada C1A 4P3
}

\begin{abstract}
Subacute ruminal acidosis (SARA) increases lipopolysaccharide endotoxin in the rumen, which might translocate into the systemic circulation, triggering a cascade of clinical and immunological alterations. The objective of this study was to characterize the clinical immune and metabolic responses to ruminal-derived lipopolysaccharide in nonlactating cows induced with SARA using 2 challenges, a grain-based SARA challenge (GBSC) or an alfalfa-pellet SARA challenge (APSC). Six dry, nonlactating Holstein cows were used in a $3 \times 3$ Latin square arrangement of treatments with 4 -wk experimental cycles. All cows received the control diet containing $70 \%$ forage and $30 \%$ mixed concentrates (dry matter basis) for 3 wk. In wk 4, cows received a control diet, GBSC (38\% wheat-barley pellets, 32\% other mixed concentrate, and $30 \%$ forages), or APSC (45\% mixed concentrate, $32 \%$ alfalfa pellets, and $23 \%$ other forages). Total plasma proteins and immunologyrelated proteins, acute phase proteins, blood cells, serum chemistry, mRNA gene expression of peripheral blood cell surface markers, and selected proinflammatory cytokines were evaluated. Ruminal $\mathrm{pH}$ was lower in both groups with induced SARA compared with a control group. Ruminal endotoxins were higher in GBSC; however, plasma endotoxin was not detected in any study group. No significant differences in feed intake, rectal temperature, white blood cell counts, or differentials were found between control and SARA challenge groups; changes in glucose, urea, $\mathrm{Ca}$, and $\mathrm{Mg}$ were observed in SARA groups. Total plasma proteins were lower in both SARA groups, and acute phase proteins were higher in GBSC. The expression of CD14, MD2, and TLR4 mRNA in peripheral blood leukocytes was not affected by SARA induction. The induction of SARA as a result of GBSC or APSC challenge was successful; however, LPS was not detected in plasma.
\end{abstract}

Received May 3, 2014.

Accepted August 22, 2014.

${ }^{1}$ Corresponding author: jrodriguez@upei.ca
Changes in clinical, metabolic, and inflammatory responses were not observed in the SARA-challenged cows, suggesting that, in this study, SARA was not associated with a systemic response to inflammation.

Key words: rumen, subacute ruminal acidosis, immune response, inflammation, metabolite

\section{INTRODUCTION}

Energy demands associated with milk production have increased the addition of grain into diet composition of dairy cows, which has now become a common practice in milk producers in North America. Similar to lactic acidosis, SARA has been associated with feeding starch-rich diets (Owens et al., 1998; Kleen et al., 2003; Plaizier et al., 2008). Unlike ruminal acidosis, SARA results from continued ingestion of these feeds over a prolonged period rather than sudden exposure without adequate adaptation (Garry and McConnel, 2008). In dairy cattle, which are not well adapted to grain and high-starch diets, the appearance of SARA is common and the ruminal $\mathrm{pH}$ is usually low within defined periods (Kleen et al., 2003). The high content of starch in grains increases grain fermentability by rumen microbes, increasing the production of shortchain fatty acids and therefore reducing ruminal $\mathrm{pH}$, which ultimately changes the composition of the rumen microflora (Zebeli and Metzler-Zebeli, 2012). High concentrations of butyric and propionic acids stimulate proliferation of the ruminal papilla epithelium (Garry and McConnel, 2008); if the proliferation of the ruminal papilla epithelium is severe, it can result in parakeratotic changes associated with decreased absorption of VFA and increased susceptibility to damage and inflammation (Steele et al., 2011). Upon induction of SARA, an increased concentration of LPS is observed within several compartments of the ruminant gastrointestinal tract (Gozho et al., 2005; Li et al., 2012). The ruminal wall lesions allow penetration of bacteria and endotoxin with dissemination to the bloodstream (Kleen et al., 2003). Consequently, the presence of systemic LPS may 
result in an immunological challenge to the animal, triggering a cascade of events associated with an immunological response within the host (Gozho et al., 2005). Consequences of SARA include feed intake depression, fluctuations in feed intake, reduced diet digestibility, reduced milk yield, reduced milk fat percentage, gastrointestinal damage, liver abscesses, and lameness (Krause and Oetzel, 2006; Plaizier et al., 2008).

The presence of LPS in the systemic circulation could engage the pattern recognition receptors, affecting leukocyte populations and triggering the production of proinflammatory cytokines and acute phase proteins (APP). Once in systemic circulation, lipopolysaccharides are recognized by a LPS receptor complex. The LPS receptor complex consists of LPS-binding protein (LBP), membrane (m) CD14, the pattern recognition receptor TLR4, and the associated protein myeloid differentiation factor 2 (MD-2; da Silva Correia et al., 2001). When engaged by LPS, such as in infections caused by gram-negative bacteria, this complex transduces a signal detected by the myeloid differentiation primary response gene $88(M y D 88)$, resulting in the activation of nuclear factor $\kappa-\mathrm{B}$, initiating a transcription of a proinflammatory cytokine cascade (Erridge et al., 2002). It might be expected that the presence of endotoxins in the gastrointestinal tract occurs in SARA and the translocation of endotoxins to the systemic circulation triggers innate immune mechanisms involving leukocyte proliferation, activation of LPS/LBP/CD4 and TLR4/MD2 complexes, upregulation of proinflammatory cytokines and production of APP, which are an integral part of the acute phase response (APR; Cray et al., 2009).

Results of both experimental induced and field SARA cases have indicated that changes in biochemical profile occur in the course of developing SARA, suggesting a possible relationship between SARA and metabolism (Riuzzi et al., 2009). In dairy cattle suffering from SARA, blood glucose and electrolyte abnormalities have been reported to be associated with the presence of LPS in systemic circulation (Khafipour et al., 2009b). However, the association between the presence of LPS in blood, innate immune response, and biochemical abnormalities in cattle with SARA is yet to be determined.

We hypothesized that experimentally induced SARA in dairy cattle triggers changes in feed intake and body temperature and results in alterations of the leukogram, biochemical profile, and innate immune response. We also hypothesized that those changes may be associated with the presence of ruminal-derived LPS. The objectives of this study were to determine whether SARA induces changes in clinical variables, systemic biochemical profile, and systemic immune response characterized by alteration of the leukogram and expression of CD14 complex on peripheral blood mononuclear cells (PBMC), and increased concentrations of APP. The second objective was to determine whether those changes were associated with the presence of ruminal-derived LPS in bloodstream. Subclinical acute ruminal acidosis was induced using 2 models previously reported (Li et al., 2012), a grain-based SARA challenge (GBSC) and an alfalfa-pellet SARA challenge (APSC).

\section{MATERIALS AND METHODS}

\section{Animals, Experimental Design, and Diets}

Six nonlactating, nonpregnant, mature $(>5$ yr) Holstein cows with average initial BW of $620 \pm 45.7 \mathrm{~kg}$ (mean $\pm \mathrm{SD}$ ) that were fitted with a ruminal and cecal cannula, were used in a replicated Latin Square experimental design with blocking on cows and periods. Cow pairs were randomly assigned to 1 of 3 treatments in 3 different periods. Each experimental period consisted of $4 \mathrm{wk}$ in which all cows received a diet consisting of $70 \%$ (DM basis) of forage in the first $3 \mathrm{wk}$. In wk 4 , cows received 1 of 3 diets. One group remained on the control diet whereas the other 2 groups received 1 of 2 SARA-induction diets, GBSC or APSC. Ingredient and nutrient composition of experimental diets are presented in Table 1; further details on the experimental diets were previously described ( $\mathrm{Li}$ et al., 2012).

Cows were transitioned from the adaptation diet to SARA-induction diets over $3 \mathrm{~d}$. The cows were housed in individual tie-stalls in the Glenlea Dairy Research Unit at the University of Manitoba (Winnipeg, MB, Canada) in accordance with the guidelines of the Canadian Council on Animal Care (CCAC, 1993). On a weekly basis, veterinarians examined cows for heart rate, respiratory rate, and rumen contractions. Rectal temperatures were recorded on sampling days of wk 3 and wk 4. The amounts of TMR offered and refused were recorded daily for each cow.

\section{Blood Collection and Hematological Analyses}

Blood samples were collected from the tail vein on d 7 of wk 3, and on d 3 and d 5 of wk 4 of each study period. Blood was collected at $0900 \mathrm{~h}$, before feeding, and at $1500 \mathrm{~h}, 6 \mathrm{~h}$ post feeding. One BD Vacutainer blood-collection tube (BD-Canada, Mississauga, ON, Canada) and one plasma $\mathrm{K}_{2}$ EDTA Vacutainer (Becton Dickinson, Franklin Lakes, NJ) were analyzed by Manitoba Agricultural, Food and Rural Initiatives Vet Diagnostics Services (Winnipeg, MB, Canada) for hematological parameters: red blood cells (RBC), packed 
Table 1. Ingredient and nutrient composition of control diet, grainbased SARA challenge (GBSC) diet, and alfalfa-pellet SARA challenge (APSC) diet used for inducing SARA

\begin{tabular}{lccc}
\hline Item & Control & GBSC & APSC \\
\hline Ingredient (\% of DM) & & & \\
Barley silage & 40 & 28 & 33 \\
Alfalfa hay $^{1}$ & 30 & 8 & - \\
Supplement $^{1}$ & 30 & 30 & 30 \\
Wheat-barley pellets $^{2}$ & - & 34 & - \\
Alfalfa pellets & - & - & 37 \\
Nutrient composition (\% of DM) & & & \\
DM (\%) & 54.3 & 61.6 & 69.0 \\
CP & 16.1 & 16.0 & 16.0 \\
NDF & 35.6 & 22.9 & 34.5 \\
ADF & 23.3 & 15.2 & 22.6 \\
NFC & 34.8 & 50.4 & 49.0 \\
Starch & 14.2 & 33.7 & 15.9 \\
Fat & 3.6 & 3.3 & 3.2 \\
Ash & 9.9 & 7.4 & 7.3 \\
Ca & 0.85 & 0.64 & 1.3 \\
P & 0.35 & 0.41 & 0.35 \\
Mg & 0.35 & 0.29 & 0.30 \\
K & 0.21 & 1.25 & 0.18 \\
Na & 0.27 & 0.28 & 0.32 \\
\hline
\end{tabular}

${ }^{1}$ Supplement composition as nutrient composition (\% of DM): DM (\%): 90.5; CP: 18.4; NDF: 14.7; ADF: 7.7; NFC: 56.3; starch: 35.6; crude fat: 3.9 ; ash: 6.7 ; Ca: 1.05 ; P: 0.67 ; K: 0.8 ; Mg: 0.5 ; Na: 0.53

${ }^{2}$ Consisted of $50 \%$ wheat and $50 \%$ barley.

${ }^{3} \mathrm{NFC}=100-(\mathrm{NDF} \%+\mathrm{CP} \%+$ crude fat $\%+$ ash $\%)$.

cell volume (PCV), hemoglobin $(\mathbf{H g B})$, mean corpuscular volume (MCV), mean corpuscular hemoglobin (MCH), mean corpuscular hemoglobin concentration (MCHC), white blood cells (WBC), differential WBC count (automated hematology analyzer, Cell-Dyn 3500 System, Abbott Laboratories, Abbott Park, IL), fibrinogen concentrations (by refractometry, Leica TS 400, Leica Microsystems Inc., Concord, ON, Canada), and selected parameters of blood chemistry such as urea, creatinine, glucose, CK, aspartate aminotransferase, $\gamma$-glutamyltransferase, alkaline phosphatase (ALKP), TTP, albumin (Alb), globulin (Glob), phosphorus, calcium, magnesium; Vitros 250 Chemistry Analyzer, Ortho-Clinical Diagnostics, Markham, ON, Canada).

\section{Plasma LPS and APP}

Blood tubes containing sodium heparin were centrifuged at $3,000 \times g$ at $19^{\circ} \mathrm{C}$ for 15 min to isolate plasma. The extracted plasma was used for LPS, LBP, serum amyloid A (SAA) and haptoglobin (Hp) analyses. Plasma tubes were allowed to clot at room temperature for $45 \mathrm{~min}$ before centrifugation at $3,000 \times g$ at $19^{\circ} \mathrm{C}$ for $15 \mathrm{~min}$. Plasma was separated and stored at $-80^{\circ} \mathrm{C}$ until used for analysis. The concentration of LPS in blood plasma was measured using chromogenic kinetic Limulus amoebocyte lysate (LAL) assay (Kinetic-QCL, Lonza Group, Basel, Switzerland) with a detection limit of 0.05 endotoxin units $(\mathbf{E U}) / \mathrm{mL}$ (Khafipour et al., 2009b). Concentrations of LBP were analyzed as previously described (Khafipour et al., 2009b) using a commercial kit (HK503, HyCult Biotechnology, Uden, the Netherlands). Serum amyloid A and Hp concentrations were measured using commercial ELISA kits (TP801 and TP-802, respectively, Tri-Delta Diagnostics Inc., Morris Plains, NJ), as described elsewhere (Gozho et al., 2005).

\section{Cell Preparation and Flow Cytometry Analyses}

Blood was collected into Vacutainers containing sodium heparin anticoagulant (Becton Dickinson). Peripheral blood mononuclear cells and PMNL were isolated via density gradient using Ficoll-Paque PLUS (GE Healthcare Bio-Sciences Corp., Piscataway, NJ), and RBC lysis buffer (Fisher Canada, Nepean, ON, Canada) as described by the University of Kansas Medical Center Flow Cytometry Core Laboratory (Kansas City, KS). Blood was first diluted with an equal volume of $1 \times$ PBS (Hyclone Laboratories, Thermo Scientific, Logan, UT), carefully layered on Ficoll-Paque, and centrifuged at $2,000 \times g$ for $25 \mathrm{~min}$ at $4^{\circ} \mathrm{C}$, discarding the upper supernatant after centrifugation. The buffy coat containing PBMC was extracted and placed in a new microcentrifuge tube. Isolated PBMC were washed several times with $1 \times \mathrm{PBS}$, and then diluted in $1 \mathrm{~mL}$ of $1 \times$ PBS for cell counting. The Ficoll-Paque layer was removed to access the granulocyte and erythrocyte layer. To every $1 \mathrm{~mL}$ of granulocyte and erythrocyte layer, $3.5 \mathrm{~mL}$ of $\mathrm{RBC}$ lysis buffer was added and incubated for $5 \mathrm{~min}$ at $37^{\circ} \mathrm{C}$ and centrifuged at 2,000 $\times g$ at $4^{\circ} \mathrm{C}$ for $5 \mathrm{~min}$; the supernatant was discarded. Isolated PMNL were washed several times with $1 \times$ PBS and then diluted in $1 \mathrm{~mL}$ of $1 \times$ PBS for cell counting.

Cell viability of PBMC and PMN populations was determined using trypan blue (Gibco, Invitrogen Canada Inc., Burlington, ON, Canada). After counting, approximately $1 \times 10^{6}$ cells $/ 100 \mu \mathrm{L}$ were placed into each well of a 96-well plate for antibody staining. Lipopolysaccharide-stimulated PBMC and PMNL were included as positive controls. These cells were stimulated with 1,000 EU/mL of purified E. coli O111:B4 LPS (Sigma-Aldrich, St. Louis, MO) and incubated for $1 \mathrm{~h}$ at $37^{\circ} \mathrm{C}$. The remaining cells were used for total RNA extraction, as described later.

Anti-bovine monoclonal antibodies against CD14 and CD11a (AbD Serotec, Raleigh, NC) were used. Antibody CD11a was used to distinguish the desired cell populations (i.e., granulocytes, lymphocytes, monocytes, and macrophages). Cells were labeled with monoclonal primary or isotype control antibodies at a 1:100 dilution. Labeled cells were incubated in the dark 
at $4^{\circ} \mathrm{C}$ for $30 \mathrm{~min}$, and then centrifuged at $2,000 \times g$ for 6 min. Cells were washed twice with $1 \times$ PBS to remove any unbound antibodies. Cells were fixed in $1 \%$ buffered formalin and left at $4^{\circ} \mathrm{C}$ overnight. For each sample, 100,000 cells were run through a BD FACScalibur flow cytometer (Becton Dickinson) and analyzed for CD14 expression using Flowjo flow cytometry analysis software (v.7.5, Tree Star Inc., Ashland, OR), and figures were developed using Cyflogic software (v.1.2.1, CyFlo Ltd., Turku, Finland).

\section{RNA Extraction and Reverse Transcription}

Allocations of PBMC and PMN cells were left in $500 \mu \mathrm{L}$ of RNAlater (Ambion, Applied Biosystems, Foster City, CA) at $4^{\circ} \mathrm{C}$ overnight. The cells were then centrifuged at $1,500 \times \mathrm{g}$ at $4^{\circ} \mathrm{C}$ for $1 \mathrm{~min}$ to remove the RNAlater and stored at $-80^{\circ} \mathrm{C}$ until used. Total RNA was extracted, within a week of storage, using TRI Reagent Solution following the manufacturer's protocol (Ambion, Applied Biosystems). The RNA pellets were resuspended in RNase- and DNase-free water (Invitrogen Canada Inc.) and stored at $-80^{\circ} \mathrm{C}$. Ten microliters of RNA was converted into cDNA using the High-Capacity cDNA Reverse Transcription Kit with RNase Inhibitor (Applied Biosystems) according to the manufacturer's protocol. The cDNA was then stored at $-80^{\circ} \mathrm{C}$ until quantitative real-time PCR analysis.

\section{Quantitative Real-Time PCR and Gene Expression Analyses}

The expression of TLR4 and MD2 was analyzed and $\beta$-actin was included as an endogenous control. The primers used for relative quantification real-time PCR and for cloning plasmid controls were designed with Primer Premier 5 Software (Premier Biosoft, Palo Alto, CA) and synthesized by University Core DNA Services (University of Calgary, Calgary, AB, Canada). The list of designed primers is located in Table 2. The National Center for Biotechnology Information (NCBI) GenBank was used to identify bovine mRNA sequences of $\beta$-actin, TLR4, and MDQ, and NCBI BLASTN (http:// blast.ncbi.nlm.nih.gov/Blast.cgi) was used to verify the specificity of the primers.

The Step One Real-Time PCR System (Applied Biosystems) and SYBR Green I dye chemistry were used for relative quantification of gene expression. The SYBR green PCR Master Mix (12.5 $\mu \mathrm{L}$; Applied Biosystems), $2 \mu \mathrm{L}$ of primers, $2 \mu \mathrm{L}$ of diluted cDNA template, and $8.5 \mu \mathrm{L}$ of water were added into each well. A concentration of $700 \mathrm{n} M$ was used for the $\beta$-actin primer and 300 $\mathrm{n} M$ was used for TLR4 and MD2 primers. All samples were initially diluted $1: 25$. If the cycle threshold value

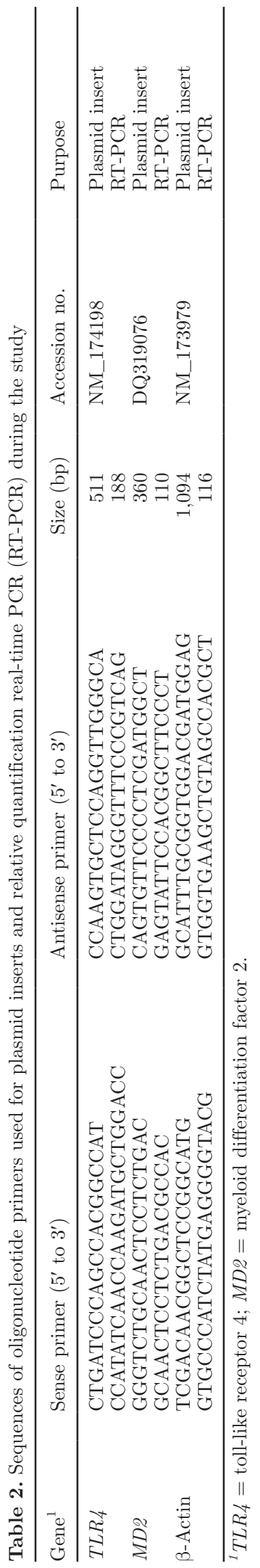


was too low, samples were further diluted to obtain a value between 15 and 30 . A plasmid template of each gene was included as a control. Template-free wells were also included. All genes were run on the same plate in duplicate. The run settings were as follows: $95^{\circ} \mathrm{C}$ for $10 \mathrm{~min}$, and 45 cycles of $95^{\circ} \mathrm{C}$ for $15 \mathrm{~s}, 55^{\circ} \mathrm{C}$ for $30 \mathrm{~s}$, and $60^{\circ} \mathrm{C}$ for $1 \mathrm{~min}$. This was followed by a 3-step melt curve. Relative quantification of gene expression was calculated using an equation reported by Pfaffl (2001).

\section{Plasmid Control Preparation}

Plasmids were prepared for each of the genes analyzed via real-time PCR to be used for primer standardization, as well as a control in real-time PCR data analysis. Partial-length coding sequences of TLR4, MD2, and $\beta$-actin were amplified from PBMC cDNA using PCR Master Mix Kit (Promega Corporation, Fisher Scientific, Nepean, ON, Canada) and a 2720 Thermo Cycler (Applied Biosystems). The PCR thermal profile for TLR 4 and MD2 was initiated by a 1-min denaturation at $94^{\circ} \mathrm{C}$, followed by 35 cycles consisting of $1 \mathrm{~min}$ of denaturation at $94^{\circ} \mathrm{C}, 45 \mathrm{~s}$ of annealing at $60^{\circ} \mathrm{C}$, and $45 \mathrm{~s}$ of elongation at $72^{\circ} \mathrm{C}$. A final 10 -min extension step was included at $72^{\circ} \mathrm{C}$ followed by a reduction in the temperature to $4^{\circ} \mathrm{C}$. The thermal profile for $\beta$-actin started with a 1 -min denaturation at $94^{\circ} \mathrm{C}, 1 \mathrm{~min}$ of annealing at $57^{\circ} \mathrm{C}$, and $1 \mathrm{~min}$ of elongation at $72^{\circ} \mathrm{C}$. A final 15 -min extension step was included at $72^{\circ} \mathrm{C}$ followed by a reduction in the temperature to $4^{\circ} \mathrm{C}$. The PCR amplicons were then isolated on a 1.5\% agarose gel, stained with ethidium bromide, and purified using Wizard SV Gel and PCR Clean-Up System (Promega Corp., Fisher Scientific). The purified PCR product was ligated into a pGEM-T vector (Promega Corp., Fisher Scientific) according to the manufacturer's protocol and transformed into E. coli competent cells (JM109; Promega Corp., Fisher Scientific). Competent cells were added to ligated product, left on ice for 20 min, heat shocked at $42^{\circ} \mathrm{C}$ for $45 \mathrm{~s}$, and then put back on ice. The transformed cells were plated on LuriaBertani agar plates containing $50 \mu \mathrm{g} / \mathrm{mL}$ ampicillin, $100 \mathrm{~m} M$ isopropyl thiogalactoside, and $20 \mathrm{mg} / \mathrm{mL} \mathrm{X-}$ gal (5-bromo-4-chloro-3-indolyl- $\beta$-D-galactopyranoside) and left at $37^{\circ} \mathrm{C}$ overnight. Five putative colonies were then transferred to liquid Terrific Broth medium and incubated overnight at $37^{\circ} \mathrm{C}$.

A basic alkaline minipreparation procedure was used to isolate plasmid DNA (Green and Sambrook, 2012). Cells were centrifuged, supernatant discarded, and pellets resuspended in $50 \mu \mathrm{L}$ of Tris-EDTA buffer containing $20 \mu \mathrm{g} / \mathrm{mL}$ of RNase A. The plasmid DNA concentration was determined at $260 \mathrm{~nm}$ (DU800 Spectrophotometer, Beckman Coulter Canada Inc., Mis- sissauga, ON, Canada). Restriction enzyme digestion (BstZ1; Promega Corporation, Fisher Scientific) and PCR amplification with gene-specific primers (Table 2 ) were used to verify the gene insert in the vector. Plasmids were stored at $-20^{\circ} \mathrm{C}$.

\section{Statistical Analysis}

The repeated measurements ( $\mathrm{d} 7$ of wk 3 , and $\mathrm{d} 5$ and d 7 of wk 4) of hematological and blood chemistry parameters, APP, flow cytometry, and quantitative real-time PCR on each cow were analyzed separately using linear mixed models (Dohoo et al., 2009). The overall resulting model to evaluate the outcomes in cow $i$ within treatments at period $j$ was as follows:

$$
y_{i j k l}=\mu+\alpha_{i}+\beta_{j}+\delta_{k}+\gamma_{l}+A_{i}+\varepsilon_{i j k l},
$$

where $y_{i j k l}$ corresponds to hematological and blood chemistry parameters, APP, flow cytometry and quantitative real-time PCR; $\mu$ is the overall mean; $\alpha_{i}$ is the treatment effect on $i$ th cow; $\beta_{j}$ represents the overall effect of $j$ th period on cow $i$ (period 1,2 , or 3 ); $\delta_{k}$ represents the effect of sample collection day (d 7 of wk 3 , and $\mathrm{d} 3$ and $\mathrm{d} 5$ of wk 4$) ; \gamma_{l}$ is the effect of time of the day $l$ (a.m. or p.m.) of day $k ; A_{i}$ is the cow random effect; and $\varepsilon_{i j k l}$ is the error term.

The statistical models included categorical effects of treatment (control, GBSC, and APSC), period, day, and time of the day; when significant, treatment groups were compared in each period by model-based tests adjusted for multiple testing by the Bonferroni method (briefly, by multiplying the resulting $P$-values by the number of tests). The models were evaluated by standardized residuals, and transformations of the outcome were explored whenever the model assumptions were not fully met (Dohoo et al., 2009). Effects were considered significant at $P<0.05$, and trends considered at $P$ $<0.10$. Analyses were carried out using the command xtmixed of the statistical package Stata (version 13.1, Stata Corp., College Station, TX).

The percentage of PBMC of control and SARAinduced cows expressing CD14 on the cell surface after stimulation with $1,000 \mathrm{EU} / \mathrm{mL}$ of Escherichia coli O111:B4 LPS for $1 \mathrm{~h}$ at $37^{\circ} \mathrm{C}(\mathrm{n}=10)$ was compared using a paired Student's $t$-test. Data collected from one cow of APSC group during period 1 were omitted from APP and blood cell differential analyses due to severe gastrointestinal parasitism.

\section{RESULTS}

Cows from both diet models developed SARA. Ruminal $\mathrm{pH}$ was $<5.6$ for 298.7 and $225.2 \mathrm{~min} / \mathrm{d}$ in GBSC and APSC, respectively, compared with $56.4 \mathrm{~min} / \mathrm{d}$ in 
Table 5. Blood chemistry of nonlactating dairy cows fed a control diet or induced (treatment) with SARA using the grain-pellet or alfalfa-pellet based diet models

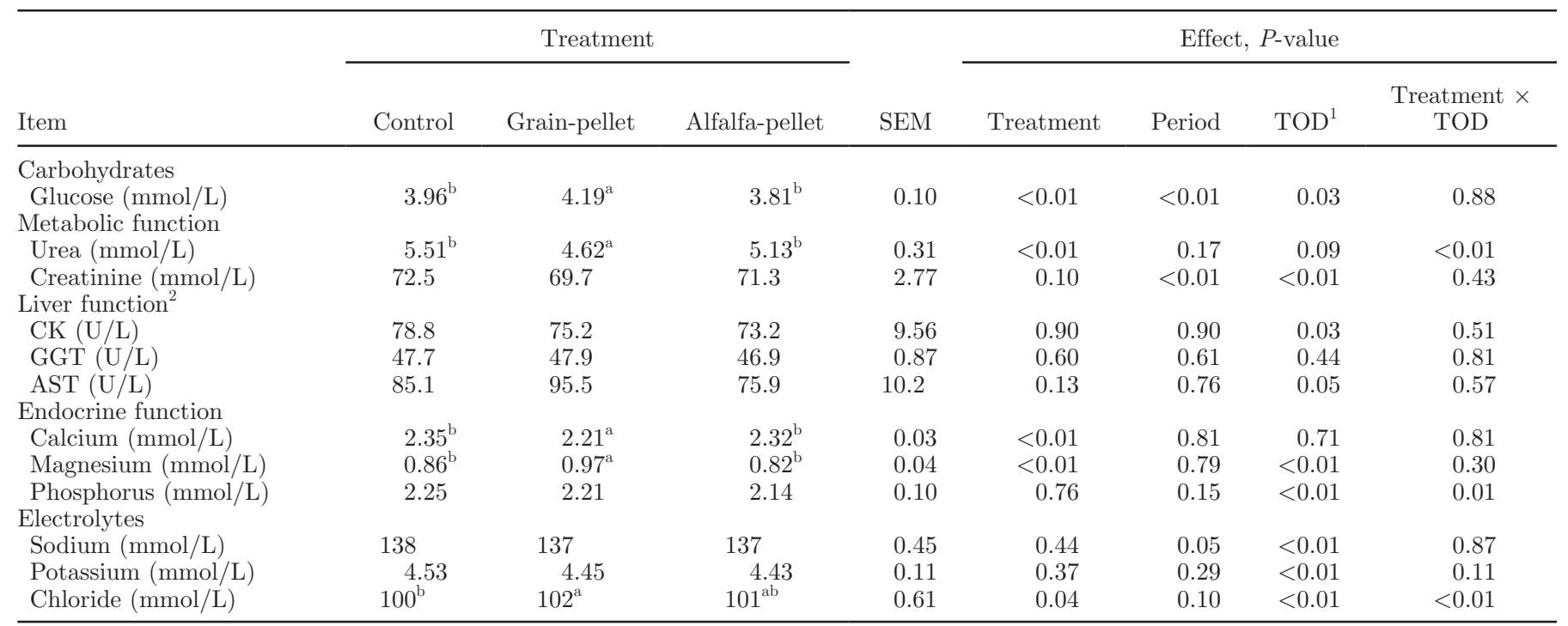

${ }^{\mathrm{a}, \mathrm{b}}$ Means within a row with different superscript letters differed $(P \leq 0.05)$.

${ }^{1} \mathrm{TOD}=$ time of day (a.m. vs. p.m.).

${ }^{2} \mathrm{CK}=$ creatine kinase; GGT $=\gamma$-glutamyl transferase; AST $=$ aspartate aminotransferase.

$(P<0.01)$. Calcium concentration was not affected by period $(P>0.05)$ : we observed no differences due to day of sample collection $(P>0.05)$. Magnesium was affected by SARA challenge, with a higher concentration detected in the GPSC group compared with control and ABSC groups $(P<0.01)$. Serum $\mathrm{P}$ concentration was similar among groups $(P>0.05$; Table 5$)$.

\section{Total Plasma Proteins and Acute Phase Proteins}

Inducing cows with SARA reduced total plasma proteins compared with control cows (Table 6). Total plasma protein concentrations were lower in both SARA challenge groups due to both hypoalbuminemia and hypogammaglobulinemia. No differences were identified between SARA groups (Table 6).

Period had a significant effect on the concentration of selected proteins and on the albumin:globulin ratio. Albumin concentration increased slightly from period 1 to period 2 and from period 2 to period $3(P<0.01)$. Period had a significant effect on fibrinogen and albumin (Table 6). Albumin concentrations increased significantly from period 1 to period $3(P=0.05)$; conversely, fibrinogen decreased significantly from period 1 to period $3(P<0.05)$. The total protein to fibrinogen ratios in both SARA induction treatments were reduced compared with the ratio of the control treatment but the difference was not significant (Table 6). The day of

Table 6. Least squares means and standard error of means of the concentration of selected proteins in nonlactating dairy cows fed a control diet or induced (treatment) with SARA feeding grains (GBSC) or alfalfa pellets (APSC)

\begin{tabular}{|c|c|c|c|c|c|c|c|c|}
\hline Item & \multicolumn{3}{|c|}{ Treatment } & $\mathrm{SEM}^{1}$ & \multicolumn{4}{|c|}{$P$-value } \\
\hline Total plasma proteins $(\mathrm{g} / \mathrm{L})$ & $83.5^{\mathrm{a}}$ & $79.6^{\mathrm{b}}$ & $80.4^{\mathrm{b}}$ & 1.71 & $<0.01$ & $<0.01$ & 0.24 & 0.15 \\
\hline Globulin (g/L) & $53.9^{\mathrm{a}}$ & $51.0^{\mathrm{b}}$ & $51.8^{\mathrm{b}}$ & 1.56 & $<0.01$ & $<0.01$ & 0.68 & 0.19 \\
\hline Fibrinogen $(\mathrm{g} / \mathrm{L})$ & 6.6 & 6.8 & 6.5 & 0.27 & 0.62 & $<0.01$ & 0.04 & 0.08 \\
\hline Albumin:globulin ratio & 0.56 & 0.57 & 0.56 & 0.02 & 0.52 & $<0.01$ & 0.77 & 0.21 \\
\hline Haptoglobin $(\mathrm{mg} / \mathrm{L})$ & $54.4^{\mathrm{b}}$ & $83.5^{\mathrm{a}}$ & $72.2^{\mathrm{b}}$ & 1.21 & 0.16 & 0.15 & 0.02 & 0.17 \\
\hline
\end{tabular}

${ }^{\mathrm{a}, \mathrm{b}}$ Means with different superscript letters differed $(P<0.05)$.

${ }^{1}$ Standard error of means for the effect of diet.

${ }^{2} \mathrm{TOD}=$ time of day (a.m. vs. p.m.). 
sample collection and the time of day had no effects on either selected proteins or their ratios (Table 6).

Concentrations of serum LBP (Table 3), SAA, and Hp were significantly higher in the GBSC cows compared with the control group $(P<0.01$; Table 6$)$. Mean plasma concentration of SAA was $38.4 \pm 1.12 \mathrm{mg} / \mathrm{L}$ in control cows and $62.6 \pm 1.12 \mathrm{mg} / \mathrm{L}(P<0.01)$ in GBSC cows. The concentrations of LBP, SAA, and Hp of cows in the APSC group were similar to those in the control group (Table 6).

\section{LPS-Associated Recognition Receptors}

The expression of endotoxin-related recognition receptors did not change due to the induction of SARA. The percentage of PBMC expressing CD14 on the cell surface did not differ between SARA groups and control treatment $(P=0.85)$. However, CD14 was not detected on the surface of PMNL.

The expression of CD14 on LPS-stimulated PBMC cells, used as a positive control, was downregulated compared with that of control cells (Figure 1). The downregulation of CD14 was accompanied by a change in cell morphology based on cell size (forward scatter) and granularity (side scatter). Both side and forward scatter of the CD14-positive population of cells expanded after LPS stimulation indicated cell differentiation.

The expression of MD2 and TLR 4 genes was detected in most PBMC and PMNL samples. Nevertheless, SARA induction did not result in differences for either target gene compared with the control diet $(P>0.05)$. All samples expressed $\beta$-actin (included as endogenous control).

\section{DISCUSSION}

The induction of SARA as a result of GBSC or APSC challenge was successful according to the definition (Kleen et al., 2003; Gozho et al., 2005). A reduction in ruminal pH below 5.6 is an essential characteristic of SARA (Krause and Oetzel, 2006). The stimulus caused by low $\mathrm{pH}(\mathrm{pH}<5.6)$ on the ruminal environment lasted $298.7 \mathrm{~min} / \mathrm{d}$ at most, indicating that cows were able to buffer transient spikes of $\mathrm{pH}$, which may prevent further damage to rumen mucosae and proliferation of the rumen papilla epithelium (Owens et al., 1998; Kleen et al., 2003). The clearance of acids from the rumen is affected by the size and density of the rumen papillae, as these determine how fast acids can be absorbed (Van Soest, 1991). A reduction in absorption (e.g., by inflammation or parakeratosis of the rumen wall due to low rumen $\mathrm{pH}$ ) increases the risk of SARA in cattle.

Recent studies have reported a coordinated adaptation of many molecular functions and pathways (i.e., epithelial proliferation, cellular function, and tissue permeability) in response to $\mathrm{pH}$ fluctuations in the rumen (Penner et al., 2010; Taniguchi et al., 2010; Dionissopoulos, 2013). The authors of a previous study concluded that a mild episode of SARA does not affect ruminal epithelial barrier function immediately after the episode; however, a more severe acidification $(\mathrm{pH}$ $\leq 5.2$ ) in vitro increases epithelial permeability following the insult (Penner et al., 2010). Furthermore, feeding diets rich in barley grain to goats was shown to decrease ruminal fluid $\mathrm{pH}$ to 5.5 and alter electrophysiological properties and permeability of the ruminal wall (Klevenhusen et al., 2013). The results of the present study suggest that the SARA challenges were not prolonged or severe enough to induce a severe lesion on the rumen mucosae to cause massive translocation of bacteria, LPS, or other pathogen-associated molecular patterns (PAMP) from the rumen to the bloodstream. Massive translocation of bacteria, LPS, or PAMP may have triggered severe systemic immune response, resulting in the development of clinical signs, such as fever and altered behavior, and changes in the leukogram parameters (Kleen et al., 2003; Dionissopoulos, 2013). Similar to previous studies (Gozho et al., 2007), the WBC and differentials in SARA-induced cows in the present study were comparable to those of control cows. Throughout the course of the experiment, total plasma proteins, globulins, fibrinogen, and albumin concentrations remained within the reference values (Jones and Allison, 2007; Russell and Roussel, 2007).

A significant increase in rumen LPS, particularly in GBSC SARA, was determined in the current study. Similar to previous studies, multiple-fold increases of

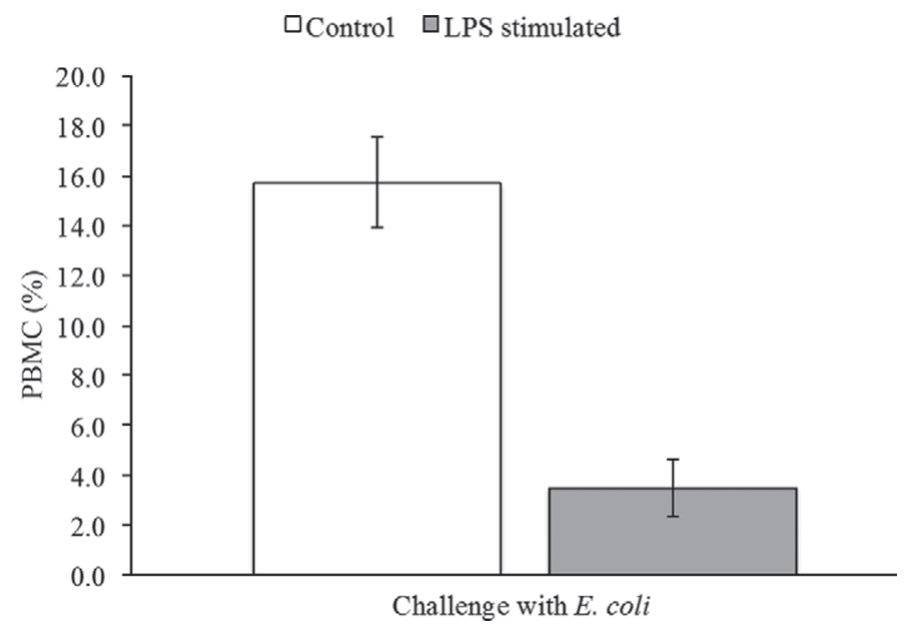

Figure 1. Percentage of peripheral blood mononuclear cells (PBMC) expressing CD14 on the cell surface after stimulation with 1,000 endotoxin units (EU)/mL Escherichia coli O111:B4 LPS for 1 $\mathrm{h}$ at $37^{\circ} \mathrm{C}(\mathrm{n}=10)$. Treatment had a significant effect at $P<0.05$. 
endotoxin concentrations in the rumen after SARA induction using either GBSC or APSC were determined (Gozho et al., 2007; Khafipour et al., 2009a; Li et al., 2012). The considerable increase of endotoxins in the rumen has been the focus of previous studies when interpreting APR-related results because LPS is capable of initiating a local immune response (Erridge et al., 2002). It has also been suggested that rumen LPS (simultaneously with other factors affecting the gastrointestinal barrier integrity such as epithelial damage due to acidic nature of the ingesta, proliferation of the ruminal papilla epithelium due to increased concentrations of VFA, and the high rumen osmolality that is seen during SARA) can cause swelling and rupture of ruminal papillae, resulting in local damage and inflammation and LPS translocation, thus leading to a systemic inflammatory response (Khafipour et al., 2009b). Comparable to previous studies (Ametaj et al., 2009; Khafipour et al., 2009b), the concentrations of plasma LBP, SAA, and Hp in the current study were significantly higher in the GBSC cows compared with the control group. The increases in plasma concentrations of the APP such as SAA and Hp do not prove translocation of LPS because these concentrations could increase due to other unspecific inflammatory stimuli. Although an increase in LBP in peripheral circulation may provide evidence of the translocation of LPS (Sriskandan and Altmann, 2008), recent studies have shown that LBP increases in response to a different PAMP (Schröder and Schumann, 2005; Ceciliani et al., 2012).

Despite general agreement that grain-induced SARA increases free rumen LPS, contradictory results regarding the presence of LPS in peripheral blood circulation have been reported (Gozho et al., 2007; Khafipour et al., 2009a). Furthermore, the detection of LPS in peripheral circulation is inconsistent during experimentally induced SARA (Khafipour et al., 2009a). Interestingly, in the present study, the plasma concentration of LBP was significantly higher in the GBSC cows but plasma LPS concentrations were not detected. One possibility for our findings is that that plasma concentration of LPS in GBSC cows was lower than the range of detection of the bioassay used in this study. In recent years, the sensitivity and accuracy of bioassays used to detect LPS have been questioned (Khafipour et al., 2009a). Therefore, it is possible that the assay used in the present study was unable to detect low concentration of LPS during the period of study. A second possibility is that translocation of LPS did not occur and that plasma LBP increased in response to translocation of PAMP such as lipoteichoic acid from the outer cell wall of various gram-positive bacteria (Sriskandan and Altmann, 2008). Two recent studies evaluating bovine extrahepatic gene expression of acute phase proteins demonstrated that the mucosa of the forestomach produce substantial amounts of LBP (Rahman et al., 2010) and SAA (Dilda et al., 2012). These findings may suggest that the forestomach, and especially the rumen, is able to mount a local acute phase response involving the innate immune system that inhibits systemic dissemination of LPS in this model of SARA. Unfortunately, ruminal concentrations of LBP and SAA were not determined in this study and further conclusions cannot be drawn. The primary biological role of LBP is to bind to free LPS to inactivate it. Subsequently, LBPLPS complex is recognized by CD14 and TLR4, stimulating leukocyte activation to produce and releasing proinflammatory cytokines (Schröder and Schumann, 2005; Ceciliani et al., 2012). However, studies have also shown the involvement of LBP in recognition of lipoteichoic acid from the outer cell wall of various gram-positive bacteria, indicating that LBP activity is not limited to LPS, challenging its specificity (Schröder and Schumann, 2005; Ceciliani et al., 2012).

Endotoxins are removed from the circulation by the mononuclear phagocyte system, and the response of mononuclear phagocytes to these LPS plays an important role in determining the severity of clinical disease (Ibeagha-Awemu et al., 2008). In the current study, flow cytometric analysis showed no change in the percentage of monocytes expressing CD14 in nonlactating cows suffering from diet-induced SARA. It has been demonstrated that the anticoagulant used to preserve the sample and processing methods affect the surface expression of $\mathrm{mCD} 14$ in bovine neutrophils and monocytes (Ibeagha-Awemu et al., 2012). Interestingly, in the current study, the positive control LPS-incubated cells revealed a downregulation of CD14 expression and an altered morphology associated with size and granulometry of the monocytes. Monocyte-derived macrophages increase in size and granularity compared with monocytes when monocytes are allowed to differentiate, which supports the differentiation of monocytes into macrophages after the detection of endotoxin (Guo et al., 2009). The consistent expression of CD14 on PBMC of SARA-induced and control treatments may suggest that endotoxins were not present or low plasma levels of LPS were insufficient to trigger an immune response.

The induction of SARA in this study did not affect the gene expression of TLR4 and MD2 on either PBMC or PMNL. A recent study focusing on the effect of LPS on TLR 4 expression in both monocytes and monocytederived macrophages found no changes in gene expression in control samples (Guo et al., 2009). However, an increase in the gene expression levels of TLR4 in the presence of LPS has been shown in other tissues, such as the mammary gland (Ibeagha-Awemu et al., 2008). It is evident some cells or tissues are refractory 
to altered expression of genes associated with LPS in the presence of LPS, suggesting that other factors are required, such as cytokines. The reason for this would be an immunological homeostasis to minimize hyperresponsiveness and constant immune response stimulation (Abreu et al., 2001).

Blood glucose concentration was significantly higher in cows of the GBSC group than in those of the control and APSC groups. The increase in glucose has previously been reported in association with GBSC (Khafipour et al., 2009a; Zebeli et al., 2011) and can be the result of an increase of propionate and butyrate in the rumen (Gozho et al., 2007; Khafipour et al., 2009a; Zebeli et al., 2011). Nevertheless, recent studies suggested that free fatty acids, such as butyrates, might have a protective effect on rumen mucosae in SARA-induced cows (Dionissopoulos, 2013). The changes observed in serum urea concentration might be due to more efficient utilization of rumen ammonia for microbial protein synthesis, as diet protein levels were similar across all the diets used in this study. Nevertheless, these metabolites were also affected by other variables, such as cycle, day of sampling, and time of day when sample was collected. Therefore, the variation in glucose and urea upon SARA induction are associated with metabolic utilization rather than indicating a systemic response to ruminal injuries.

Serum $\mathrm{Ca}$ and $\mathrm{Mg}$ concentrations were significantly affected in cows with SARA challenges. However, their concentrations remained within accepted reference values. Although the role of macrominerals, such as Ca and $\mathrm{Mg}$, and microminerals in the immunological response of cattle has been recognized for many years (Spears and Weiss, 2008), understanding of the biological roles associated with SARA induction and feeding grain-rich diets is limited and requires further investigation. Nevertheless, strong inverse relationships between ruminal endotoxins and plasma $\mathrm{Ca}$ and between SAA and $\mathrm{Ca}$ have been recently reported (Zebeli et al., 2010). Although the alterations in serum $\mathrm{Ca}$ concentration were statistically significant, the magnitude of those changes was too minor to have clinical significance.

\section{CONCLUSIONS}

Our results did not support changes in the health or immune status of the cows, as evaluated by changes in behavior or rectal temperature, WBC population, or total plasma proteins in association with SARA induction. However, mild changes in APP were observed in cows with diet-induced SARA, particularly in the GBSC challenge group. The results of the present study may indicate that the SARA challenges were not prolonged or severe enough to cause a severe lesion on the rumen mucosae that would allow massive translocation of bacteria, LPS, or other PAMP from rumen to the bloodstream and trigger a systemic immune response, resulting in the development of clinical signs, such as fever and altered behavior, and changes in the leukogram. Nevertheless, the question that remains is whether changes in APP indicate a systemic response or a local immune response. Although LPS concentrations significantly increased in the rumen, the specificity of LBP to LPS is still under debate. Our results indicate that the increase in serum LBP in GBSC was moderate, not necessarily resulting from the presence of LPS in systemic circulation, which might indicate functions of LBP other than binding to LPS. Future research is warranted to determine whether SARA induces systemic inflammatory response depending on the severity and duration of the stimuli on the ruminal epithelium.

\section{REFERENCES}

Abreu, M. T., P. Vora, E. Faure, L. S. Thomas, E. T. Arnold, and M. Arditi. 2001. Decreased expression of Toll-like receptor-4 and MD-2 correlates with intestinal epithelial cell protection against dysregulated proinflammatory gene expression in response to bacterial lipopolysaccharide. J. Immunol. 167:1609-1616.

Ametaj, B. N., K. M. Koenig, S. M. Dunn, W. Z. Yang, Q. Zebeli, and K. A. Beauchemin. 2009. Backgrounding and finishing diets are associated with inflammatory responses in feedlot steers. J. Anim. Sci. 87:1314-1320.

CCAC. 1993. Guide to the Care and Use of Experimental Animals. 2nd ed., Vol. 1. Canadian Council on Animal Care, Ottawa, ON Canada.

Ceciliani, F., J. J. Ceron, P. D. Eckersall, and H. Sauerwein. 2012 Acute phase proteins in ruminants. J. Proteomics 75:4207-4231.

Cray, C., J. Zaias, and N. H. Altman. 2009. Acute phase response in animals: A review. Comp. Med. 59:517-526.

da Silva Correia, J., K. Soldau, U. Christen, P. S. Tobias, and R. J. Ulevitch. 2001. Lipopolysaccharide is in close proximity to each of the proteins in its membrane receptor complex: Transfer from CD14 to TLR4 and MD-2. J. Biol. Chem. 276:21129-21135.

Dilda, F., L. F. Pisani, M. M. Rahman, S. Modina, I. Tessaro, P. Sartorelli, F. Ceciliani, and C. Lecchi. 2012. Distribution of acute phase proteins in the bovine forestomachs and abomasum. Vet. J. 192:101-105.

Dionissopoulos, L. 2013. Understanding the molecular mechanisms involved in subacute ruminal acidosis and rumenitis. $\mathrm{PhD}$ Thesis. University of Guelph, Guelph, ON, Canada.

Dohoo, I., W. Martin, and H. Stryhn. 2009. Veterinary Epidemiologic Research. 2nd ed. AVC Inc., Charlottetown, PEI, Canada.

Erridge, C., E. Bennett-Guerrero, and I. R. Poxton. 2002. Structure and function of lipopolysaccharides. Microbes Infect. 4:837-851.

Garry, F., and C. McConnel. 2008. Indigestion in ruminants. Pages 829-830 in Large Animal Internal Maedicine. 4th ed. B. Smith, ed. Mosby/Elsevier, St Louis, MO.

Gozho, G. N., D. O. Krause, and J. C. Plaizier. 2007. Ruminal lipopolysaccharide concentration and inflammatory response during grain-induced subacute ruminal acidosis in dairy cows. J. Dairy Sci. 90:856-866.

Gozho, G. N., J. C. Plaizier, D. O. Krause, A. D. Kennedy, and K. M. Wittenberg. 2005. Subacute ruminal acidosis induces ruminal lipopolysaccharide endotoxin release and triggers an inflammatory response. J. Dairy Sci. 88:1399-1403.

Green, M. R., and J. Sambrook. 2012. Isolation and quantification of DNA. Pages 11-80 in Molecular Cloning: A Laboratory Manual. Vol. 1. 4th ed. M. R. Green and J. Sambrook, ed. Cold Spring Harbor Laboratory Press, Cold Spring Harbor, NY. 
Guo, Y., G. Zhao, S. Tanaka, and T. Yamaguchi. 2009. Differential responses between monocytes and monocyte-derived macrophages for lipopolysaccharide stimulation of calves. Cell. Mol. Immunol. $6: 223-229$

Ibeagha-Awemu, E. M., A. E. Ibeagha, and X. Zhao. 2012. The influence of different anticoagulants and sample preparation methods on measurement of mCD14 on bovine monocytes and polymorphonuclear neutrophil leukocytes. BMC Res. Notes 5:93.

Ibeagha-Awemu, E. M., J. W. Lee, A. E. Ibeagha, and X. Zhao. 2008. Bovine CD14 gene characterization and relationship between polymorphisms and surface expression on monocytes and polymorphonuclear neutrophils. BMC Genet. 9:50.

Jones, M. L., and R. W. Allison. 2007. Evaluation of the ruminant complete blood cell count. Vet. Clin. North Am. Food Anim. Pract. 23:377-402.

Khafipour, E., D. O. Krause, and J. C. Plaizier. 2009a. Alfalfa pelletinduced subacute ruminal acidosis in dairy cows increases bacterial endotoxin in the rumen without causing inflammation. J. Dairy Sci. 92:1712-1724.

Khafipour, E., D. O. Krause, and J. C. Plaizier. 2009b. A grain-based subacute ruminal acidosis challenge causes translocation of lipopolysaccharide and triggers inflammation. J. Dairy Sci. 92:10601070.

Kleen, J. L., G. A. Hooijer, J. Rehage, and J. P. Noordhuizen. 2003. Subacute ruminal acidosis (SARA): A review. J. Vet. Med. A Physiol. Pathol. Clin. Med. 50:406-414.

Klevenhusen, F., M. Hollmann, L. Podstatzky-Lichtenstein, R. Krametter-Frötscher, J. R. Aschenbach, and Q. Zebeli. 2013. Feeding barley grain-rich diets altered electrophysiological properties and permeability of the ruminal wall in a goat model. J. Dairy Sci. 96:2293-2302.

Krause, M. K., and G. R. Oetzel. 2006. Understanding and preventing subacute ruminal acidosis in dairy herds: A review. Anim. Feed Sci. Technol. 126:215-236.

Li, S., E. Khafipour, D. O. Krause, A. Kroeker, J. C. RodriguezLecompte, G. N. Gozho, and J. C. Plaizier. 2012. Effects of subacute ruminal acidosis challenges on fermentation and endotoxins in the rumen and hindgut of dairy cows. J. Dairy Sci. 95:294-303.

Owens, F. N., D. S. Secrist, W. J. Hill, and D. R. Gill. 1998. Acidosis in cattle: A review. J. Anim. Sci. 76:275-286.

Penner, G. B., M. Oba, G. Gabel, and J. R. Aschenbach. 2010. A single mild episode of subacute ruminal acidosis does not affect ruminal barrier function in the short term. J. Dairy Sci. 93:4838-4845.

Pfaffl, M. W. 2001. A new mathematical model for relative quantification in real-time RT-PCR. Nucleic Acids Res. 29:e45.

Plaizier, J. C., D. O. Krause, G. N. Gozho, and B. W. McBride. 2008. Subacute ruminal acidosis in dairy cows: The physiological causes, incidence and consequences. Vet. J. 176:21-31.
Rahman, M. M., C. Lecchi, G. Avallone, P. Roccabianca, P. Sartorelli, and F. Ceciliani. 2010. Lipopolysaccharide-binding protein: Local expression in bovine extrahepatic tissues. Vet. Immunol. Immunopathol. 137:28-35.

Riuzzi, S., C. Cannizzo, M. Gianesella, and M. Morgante. 2009. Subacute ruminal acidosis in field conditions in the north of Italy: Epidemiology and systemic-metabolic effects investigation.Pages 105-107 in 14th Dairy Research Symposium 2009, University of Sydney: Current Topics in Dairy Production, Vol 14. Sydney, Australia.

Russell, K. E., and A. J. Roussel. 2007. Evaluation of the ruminant serum chemistry profile. Vet. Clin. North Am. Food Anim. Pract. 23:403-426.

Schröder, N. W., and R. R. Schumann. 2005. Non-LPS targets and actions of LPS binding protein (LBP). J. Endotoxin Res. 11:237242

Spears, J. W., and W. P. Weiss. 2008. Role of antioxidants and trace elements in health and immunity of transition dairy cows. Vet. J. $176: 70-76$.

Sriskandan, S., and D. M. Altmann. 2008. The immunology of sepsis. J. Pathol. 214:211-223.

Steele, M. A., J. Croom, M. Kahler, O. AlZahal, S. E. Hook, K. Plaizier, and B. W. McBride. 2011. Bovine rumen epithelium undergoes rapid structural adaptations during grain-induced subacute ruminal acidosis. Am. J. Physiol. Regul. Integr. Comp. Physiol. 300:R1515-R1523.

Taniguchi, M., G. B. Penner, K. A. Beauchemin, M. Oba, and L. L. Guan. 2010. Comparative analysis of gene expression profiles in ruminal tissue from Holstein dairy cows fed high or low concentrate diets. Comp. Biochem. Physiol. D Genomics Proteomics $5: 274-279$

Van Soest, P. J., J. B. Robertson, and B. A. Lewis. 1991. Methods for dietary fiber, neutral detergent fiber, and nonstarch polysaccharides in relation to animal nutrition. J. Dairy Sci. 74:3583-3597.

Zebeli, Q., S. M. Dunn, and B. N. Ametaj. 2010. Strong associations among rumen endotoxin and acute phase proteins with plasma minerals in lactating cows fed graded amounts of concentrate. J. Anim. Sci. 88:1545-1553.

Zebeli, Q., S. M. Dunn, and B. N. Ametaj. 2011. Perturbations of plasma metabolites correlated with the rise of rumen endotoxin in dairy cows fed diets rich in easily degradable carbohydrates. J. Dairy Sci. 94:2374-2382.

Zebeli, Q., and B. U. Metzler-Zebeli. 2012. Interplay between rumen digestive disorders and diet-induced inflammation in dairy cattle. Res. Vet. Sci. 93:1099-1108. 